\title{
OS CAMINHOS POSSÍVEIS DE UM DESGOVERNO DIANTE DA PRÁTICA DA TORTURA: APONTAMENTOS E PERSPECTIVAS NUM CONTEXTO DE APOIO GOVERNAMENTAL A GRAVES VIOLAÇÕES DE DIREITOS HUMANOS NO BRASIL
}

Paulo Endo é psicanalista e professor do Instituto de Psicologia da Universidade de São Paulo (USP). São Paulo, SP, Brasil.E-mail: pauloendo@uol.com.br Orcid: 0000-0003-3993-4786 http://dx.doi.org/10.1590/0102-177193/108

É bastante comum e ingênuo acreditar na erradicação de violações de direitos humanos (DH), levando-se em consideração os direitos lavrados na Declaração Universal dos Direitos Humanos (DUDH) de 1948. É comum porque há, em muitos de nós, o desejo de que aqueles padrões morais e civilizatórios que defendemos e consideramos representados na DUDH sejam exequíveis e, se colocados em prática, possam, por transmissão, ensino ou persuasão, se tornar uma realidade planetária.

Infelizmente não há país que tenha chegado completamente a essa conquista e, muito provavelmente, não haverá. Não conseguimos erradicar as violações aos direitos humanos como conseguimos erradicar a malária, o sarampo ou a paralisia infantil em alguns países.

A comparação não é ocasional. Trata-se de dois campos epistêmicos distintos, dois modos de combater sofrimentos humanos também diferentes e que supõem estratégias de enfrentamento que apenas num ou noutro ponto podem coincidir para sua concretização. O principal deles talvez seja a disposição irresoluta dos governos em fazê-lo. 
Pode-se realizar a vacinação em massa, mas não conseguiremos aplicar direitos humanos em massa. Isso porque eles não são alcançáveis a não ser a partir de modificações profundas nas instituições e no modo de pensar, sentir e viver das pessoas para que os direitos humanos se convertam em formas inerciais de convívio e justiça, que só ocasionalmente convocam o direito para sua concretização. É possível, portanto, de outro modo encontrar comunidades, grupos e lugares onde predominam os direitos humanos sem a interveniência de quaisquer aparatos judiciais para alcançá-los.

Mas é preciso também que as nações atuem em concerto e que as medidas para a consolidação de uma cultura pelos direitos humanos sejam mais prevalentes do que as ações para destruí-los. Infelizmente isso também ainda não ocorreu.

No final da Primeira Guerra que devastou países inteiros e ceifou a vida de milhões de cidadãos europeus, 178 Freud (2010, p. 224) observou:

Das discussões precedentes retiramos o consolo de que era injustificada nossa amargura e dolorosa desilusão pela conduta incivilizada de nossos concidadãos do mundo nessa guerra. Fundava-se numa desilusão a que nos havíamos entregado. Na realidade eles não desceram tão baixo, porque não tinham se elevado tanta quanto acreditávamos.

Essa frase lapidada pela ironia, ao ser devolvida para o campo psicanalítico onde se originou, sugere ao menos duas coisas:

1. a de que as fantasias que temos sobre nós e sobre quem somos são elementos que condensam fatos e formas de sentir e pensar compartilhadas que, entretanto, não suportam a prova da realidade. Diante dessa prova abre-se um fosso de obscuridade que sinaliza 
que o desejo pelo novo não produziu de fato o novo e seria preciso inventar caminhos não existentes ainda para alcançá-lo. Diante disso a possibilidade de retroceder, retroagir, regredir ao conhecido é imensa efeito do que Freud denomina ilusão.

2. as repetições de padrões sociais inconscientemente determinados e reproduzidos pelos sujeitos e instituições zombam das intenções mais auspiciosas e as convertem em irrealidades, máscaras e escaramuças que permanentemente postergam conquistas mais ou menos definitivas ou estáveis. Enquanto suspensos nessas irrealidades, é impossível enfrentar os desafios que elas escamoteiam.

Em artigo recente (Endo, 2018), dei continuidade a uma reflexão que realizo de modo descontínuo ao menos desde 2006 (Endo, 2006, 2010, 2014, 2018a, 2018b). Especialmente no último artigo publicado, procurei avaliar brevemente a imobilidade do Estado e das instituições brasileiras no controle e combate à tortura no país, pelo menos nos últimos catorze anos.

Partindo do ano da apresentação do Relatório sobre a tortura no Brasil, de autoria de Nigel Rodley (2001), então relator da Organização das Nações Unidas (ONU) sobre a tortura, é possível perceber que praticamente nenhuma das trinta recomendações do relator foi levada a sério e implementada com a urgência, a necessidade e até mesmo a facilidade que o relatório indicava.

Utilizei-me, naquela ocasião, dos dados relativos a locais de detenção levantados pelo Mecanismo Nacional de Prevenção e Combate à Tortura, em seu último relatório de 2016. Nessa comparação, pode-se perceber com clareza que não apenas a prática da tortura adquire um aspecto de crime continuado nos locais de detenção, como a magnitude do problema parece ficar completamente fora das políticas de 
segurança dos governos e dos parlamentares em diferentes estados da Federação e longe dos holofotes das mídias.

O relator da ONU sobre a tortura, Juan Méndez, faz uma nova visita ao Brasil em 2015. Em seu relatório constatamos problemas muito semelhantes aos encontrados em 2001: maus-tratos e torturas generalizadas, ameaças aos que delatam ou denunciam os maus-tratos sofridos, utilização abusiva de armas não letais, produção e provocação de tensão desnecessária dentro do ambiente prisional, gerando permanente estado de atenção, desconforto e medo nos detentos no sistema prisional. Em inspeção no interior dos locais de detenção, foram encontrados funcionários do sistema fortemente armados, portando rifles, espingardas e pistolas, incluindo um lançador de granadas no ambiente da prisão. Um estado de guerra sem leis e sem limites constitui o ambiente prisional no país.

O relator especial sobre a tortura acrescenta ainda que:

A tortura e os maus-tratos dessa natureza constituem uma prática arraigada e pervasiva que tem sido naturalizada a tal ponto que os prisioneiros não a mencionam, a não ser que sejam perguntados sobre isso. (Rodley, 2001, p. 11)

Quatorze anos antes, no parágrafo 166 de seu relatório, Nigel Rodley (2001, p. 12) concluía:

A tortura e maus-tratos semelhantes são difundidos de modo generalizado e sistemático na maioria das localidades visitadas pelo Relator Especial no país e, conforme sugerem testemunhos indiretos apresentados por fontes fidedignas ao Relator Especial, na maioria das demais partes do país também. A prática da tortura pode ser encontrada em todas as fases de detenção: prisão, detenção preliminar, outras formas de prisão provisória, bem como em penitenciárias e instituições destinadas 
a menores infratores. Ela não acontece com todos ou em todos os lugares; acontece, principalmente, com os criminosos comuns, pobres e negros que se envolvem em crimes de menor gravidade ou na distribuição de drogas em pequena escala. E acontece nas delegacias de polícia e nas instituições prisionais pelas quais passam esses tipos de transgressores. Os propósitos variam desde a obtenção de informação e confissões até a lubrificação de sistemas de extorsão financeira. A consistência dos relatos recebidos, o fato de que a maioria dos detentos ainda apresentava marcas visíveis e consistentes com seus testemunhos, somados ao fato de o Relator Especial ter podido descobrir, em praticamente todas as delegacias de polícia visitadas, instrumentos de tortura conforme os descritos pelas supostas vítimas, tais como barras de ferro e cabos de madeira, tornam difícil uma refutação das muitas denúncias de tortura trazidas à sua atenção.

Indubitavelmente a tortura continua sendo prática generalizada no país como uma linha contínua que não sofreu qualquer inflexão desde o fim do regime civil-militar, sobretudo nos locais de detenção espalhados pelo país. A letargia de mais de uma década indica a explícita tolerância de governos a tais práticas cometidas por agentes de segurança nos estados. No que tange às constatações e à persistência de graves violações dos direitos humanos em território nacional, os relatórios citados são pródigos e explícitos ao identificar uma verdadeira epidemia de práticas cruéis e degradantes.

A preocupação que enseja este artigo é refletir sobre como se comportará, a partir de 2019, um governo majoritariamente composto por militares, tendo como seu líder um presidente que apoia abertamente a prática da tortura e outras práticas discricionárias do passado, como as cometidas pelo ex-presidente chileno Augusto Pinochet e do conhecido torturador e assassino brasileiro Carlos Brilhante 
Ustra. Contudo é muito importante considerar também que o atual governo, que tomou posse em janeiro de 2019, é herdeiro direto de um contexto de quase total imobilidade dos governos anteriores no combate à tortura no Brasil.

Essa preocupação, que hoje assume gravidade extrema diante do histórico de impunidade e proliferação de tais práticas pelas forças de segurança no país, merece considerar a tortura como parte de um sistema que, no Brasil, a mantém, a consagra e a aprofunda há décadas, implícita ou explicitamente. Esse sistema não é necessariamente inerente a governos militares, embora tais práticas tenham sido comumente utilizadas nesses casos como instrumento violentíssimo nos interrogatórios contra nacionais para, suposta e paradoxalmente, obter informações de "segurança nacional" torturando, ameaçando e matando cidadãos do próprio país.

O estabelecimento dessa correlação direta e inercial entre a prática da tortura e os governos militares se deve, 182 obviamente, ao uso em larga escala de tais práticas pelos governos militares na América Latina no passado recente e, também, a continuidade de seu uso como prática ilegal pelas forças de segurança, hoje atuantes na maioria desses países que apresentam índices altíssimos de violências por parte das forças de segurança, mas que teoricamente são considerados países onde vigem regimes democráticos.

A persistência desse tema nas Américas, hoje incluídos os Estados Unidos e, particularmente, o Brasil, é o que interessa prosseguir analisando neste artigo. Precisaremos, contudo, considerar as influências de além-mar.

Tomemos como exemplo uma parte conhecida do depoimento do tenente-general argentino Martín Antonio Balza, então chefe de Estado das Forças Armadas. O primeiro membro graduado das Forças Armadas da Argentina a romper o silêncio, em 1995, após anos de mutismo dos militares sobre os crimes cometidos durante a ditadura argentina.

Cito um trecho do longo e conhecido depoimento: 
Sem buscar palavras inovadoras, mas apelando aos velhos regulamentos militares, aproveito esta oportunidade para pedir novamente ao exército, na presença de toda a sociedade: ninguém é obrigado a cumprir uma ordem imoral ou se desvia da lei ou regulamentos militares. Quem faz isso, incorre em uma conduta viciosa, digna da sanção que sua severidade exige. Sem eufemismos, digo claramente: criminoso que viola a Constituição Nacional. Delinque quem transmite ordens imorais. Delinque que para cumprir um propósito que acredita justo usa meios injustos e imorais. Entender esses aspectos essenciais faz a vida republicana de um Estado... Entenda isso, abandonar a visão apocalíptica, o orgulho, aceitar a dissidência e respeitar a vontade soberana, é o primeiro passo. Estamos a caminho para nos próximos anos deixar para trás o passado, para ajudar a construir a Argentina do futuro, uma Argentina amadurecida na dor, que pode um dia alcançar o abraço fraterno. Se não pudermos elaborar o luto e fechar as feridas, não teremos um futuro. Não devemos mais negar o horror vivido, e assim sermos capazes de pensar em nossa vida como uma sociedade à frente, superando o pesar e o sofrimento. ${ }^{1}$

Importa destacar nesse depoimento uma tentativa de retomada dos princípios que rezam os "velhos regulamentos militares" na Argentina, que a influência francesa viria a contaminar. Os assessores franceses ensinariam, com sucesso, aos militares argentinos estratégias de como subverter a própria função institucional das Forças Armadas em nome de um perigo maior, acima de quaisquer regulamentos. A pronta adesão a esses ensinamentos viria a manchar perenemente a imagem dos militares latino-americanos no futuro.

1 Disponível em: es.wikisource.org/wiki/Declaraci\%C3\%B3n_del_General_ Mart\%C3\%ADn_Balza_del_25_de_abril_de_1995_(Autocr\%C3\%ADtica). Acesso em: 1 mar. 2019. 
Para Balza, o mais fundamental nessa estratégia consistiu na invenção francesa da existência do "inimigo interno".

Em entrevista concedida a Marie-Monique Robin (2008, pp. 200-201) em 2003, diz Balza sobre a influência francesa na Argentina: "O horror que se desenrolou na Argentina de 1976 a 1982 é de tal modo extraordinário, de tal modo enorme que se coloca primeiro o termo impensável, quer dizer que nós não podemos pensá-lo”. E mais adiante:

eu diria que foi um cocktail político, ideológico, militar e religioso que engendrou o regime mais criminoso de nossa história. E, para a constituição desse cocktail, o ensinamento dispensado pelos assessores militares franceses a partir dos anos 1950 desempenhou um papel fundamental. Juntaria-se em seguida - mas o mal maior já havia sido feito - a influência dos norte-americanos. (Robin, 2008, pp. 200-201)

Pergunta Marie-Monique Robin (2008, p. 201): "Porque você fala de mal?”, e Balza responde:

Porque os franceses aportaram na Argentina uma concepção nefasta e perversa que literalmente envenenou o espírito dos oficiais de minha geração: essa do "inimigo interior". Até a sua chegada, nosso exército, como qualquer exército do mundo, se preparava para se defender contra um agressor eventual de um inimigo exterior, na ocorrência para nós de um país vizinho como Chile ou Paraguai.

A partir do momento em que foi introduzido o conceito de "inimigo interior", nós todos interiorizamos o fato de que o inimigo contra o qual nós tínhamos que confrontar era nosso próprio concidadão: era esse com o qual nós podíamos estar no trem pela manhã, o professor de nossos filhos ou nosso vizinho, enfim todos esses com os quais nós não compartilhamos as mesmas ideias e que poderiam ter, de perto ou de longe, afinidades com o comunismo 
apresentado como o mal absoluto, ou com o movimento peronista apresentado como um subproduto do primeiro. Em outros termos, ao longo das conferências, artigos nas revistas militares e de exercícios de engajamento, os assessores franceses, depois seus alunos argentinos, que terminariam por ultrapassar seus "mestres", não cessaram de nos dizer que o campo de batalha era o território argentino ele mesmo e que, para destruir as ideias subversivas que colocavam em perigo os valores cristãos de nossa civilização ocidental, era preciso destruir o homem ele mesmo. De fato, a partir do fim dos anos 1950 até a vinda do golpe, em março de 1976, o exército se preparava para desencadear uma guerra fratricida e a se comportar como um verdadeiro exército de ocupação em seu próprio território.

(Robin, 2008, p. 201)

Esse depoimento, bastante conhecido e peculiar, toca em pontos de grande importância em três aspectos que me interessam destacar:

1. a longa preparação técnica, teórica e psíquica para a prática da tortura, mortes e desaparecimentos iniciada nos anos 1950 pela escola francesa e que seria desencadeada, mais de vinte anos depois, em 1976, em território argentino, no Brasil, na Venezuela e no Chile.

2. a perversão e o enfraquecimento do papel das forças armadas a partir da definição e interiorização da convicção de um "inimigo interior”.

3. a convicção na continuidade nas graves violações que passaram a ocorrer, mesmo após a ONU ter adotado a DUDH em 1948, demonstra por outro lado o uso da DUDH como véu encobridor de práticas incompatíveis como a cultura nascente dos direitos humanos - 
completamente desprezada pelo governo francês -, mas inteiramente compatíveis com as estratégias de domínio aprendidas e desenvolvidas pelos países vencedores na Segunda Guerra e, no caso da França, nas guerras coloniais. O que fora aprendido e transmitido pelos aliados na guerra zombava então do que fora anunciado na recém-declarada DUDH.

Os governos militares na América do Sul sabiam que cometiam ilegalidades se utilizando sistematicamente da tortura, razão pela qual não a admitiam publicamente como prática de governo. Tal como o governo francês sabia que violava a DUDH de 1948, que fora um dos efeitos da vitória dos países aliados, que prontamente condenaram as atrocidades encontradas nos campos de concentração e extermínio alemães.

Não apenas os governos franceses deram as costas para a DUDH, por eles mesmos consignada, como praticaram, replicaram e transmitiram para outros continentes tais práticas, produzindo, nos países por eles influenciados, feridas que jamais cicatrizaram. Entre tantas, uma se destaca: a possibilidade de continuamente praticar graves violações aos direitos humanos em países colonizados e em outros continentes, descumprindo o compromisso com a DUDH, ao mesmo tempo em que defendia esses mesmos direitos na cena pública e na política internacional. A pedagogia do cinismo se somava ao ensino das técnicas e instrumentos de tortura e repressão.

Ao mesmo tempo em que o exército francês se utilizava sistematicamente, no final da década de 1940, de práticas de tortura na Indochina e, a partir de 1957, recorrentemente na Argélia, se vangloriava de ser um dos cofundadores da DUDH poucos anos antes e se ufanava da chamada "resistência francesa" e de ser um dos 
protagonistas entre os países aliados que haviam vencido a barbárie nazista em 1945 .

Os conceitos que criam as condições propícias à tortura nos países da América do Sul, do ponto de vista de sua autorização, logística, aparelhamento e prática comum, são os de segurança nacional e de inimigo interno. Entretanto a doutrina do inimigo interno francês precede à de soberania nacional americana.

Esses conceitos ganharam força e notoriedade em práticas aprendidas, transmitidas e desenvolvidas nas tensões entre países colonizados e colonizadores no século XX. A França foi uma exportadora de tais conceitos e práticas na Argentina e no Brasil que depois se disseminariam por outros países sul-americanos e que, até hoje, estão presentes tanto nas práticas e técnicas de tortura como afogamentos, choques elétricos e pau de arara quanto no modo como as nações vencedoras da segunda guerra se apresentaram e se apresentam como democracias e respeitadoras dos direitos humanos em tribunas internacionais e diante de organismos internacionais de proteção aos direitos humanos, tal como fez o governo francês no final de década de 1940 e na década de 1950 nos conflitos coloniais.

Não apenas os conceitos, as técnicas e os traumas insuperáveis foram transmitidos como marcas nacionais herdadas dos franceses em países sul-americanos, mas também a hipocrisia diante do falso compromisso e do falso protagonismo na preservação e consolidação de práticas compatíveis com a democracia e com os direitos humanos.

A chamada "guerra suja", praticada na Indochina desde a década de 1940 - mesmo período em que era lavrada a DUDH -, evidencia isso. Cito Monique Robin (2008, p. 54): 
Em 29 de julho de 1949, o jornalista Jacques Chegaray reportaria, num artigo publicado em Testemunho Cristão, a visita que ele realizou num posto de brousse de Phul Cong em Tonkin:

Aqui é meu escritório, explica o oficial francês. A mesa, a máquina de escrever e o lavabo e lá, no canto a máquina de fazer falar. [...] Sim, o dínamo. É bem cômodo para o interrogatório dos prisioneiros. O contato, o polo positivo e o polo negativo; nós viramos e o prisioneiro cospe!

Henry Ainley, um antigo legionário do corpo expedicionário francês, testemunha em 1955: "Nós não falávamos em sequestros, apropriações, torturas, mas em expedição punitiva, recuperação de material, interrogatórios" (Robin, 2008, p. 55).

Poucos anos depois, o exército francês aplicaria amplamente a tortura e criaria na Argélia os centros de detenção 188 clandestinos como locais onde se realizava a prática corriqueira de interrogatório, durante os conflitos da guerra colonial entre os grupos pela independência (FLN) e o governo e o exército francês (Robin, 2008).

A França foi, portanto, após o fim da Segunda Guerra, uma contumaz violadora transnacional dos direitos humanos empenhada durante décadas no desenvolvimento, aplicação e transmissão da prática da tortura em países colonizados, nos Estados Unidos e na América do Sul.

A escola francesa dos esquadrões da morte e da tortura fez escola na América Latina, e a prática da tortura vinha alicerçada pelos "bons resultados" alcançados nos conflitos entre o exército francês, liderado pelo coronel Philippe Mathieu, e os grupos pela independência que se sublevaram, em 1957, pela independência da Argélia.

Mathieu foi um veterano de guerra, tendo atuado na força de resistência francesa contra a ocupação alemã, na guerra da Indochina e na batalha de Argel. Trazia na bagagem os métodos 
que orgulham dos militares e a motivação de que a função "humanitária" da tortura pode evitar a morte de mulheres e crianças, como disse em entrevista de 2008 Paul Aussaresses, ex-agente do serviço secreto francês, veterano das Guerras da Indochina e da Argélia, e que contribuiu diretamente com o regime militar no Brasil durante os anos 1964-1985. ${ }^{2}$

O comunismo, por suposto, para Aussaresses, era um risco iminente para mulheres e crianças e, assim, era preciso acabar com o comunismo e os comunistas, inclusive mulheres e crianças, como ocorreu na Argélia. A produção de falseamentos de julgamento tem como principal anteparo o horror e a prática continuada da ameaça, perpetrada pela autoridade maior do Estado contra aqueles que foram definitivamente caracterizados como comunistas (os inimigos internos). Articula-se desse modo a fratura entre categorias de cidadãos comprovados a posteriori pela violência que recairá sobre eles.

Foi torturado, assassinado e desaparecido porque era comunista, e não era comunista, por isso foi torturado. Até porque essa demonstração era, muitas vezes, condenada conceitualmente pela própria caricatura grotesca que as políticas de soberania nacional do pós-Segunda Guerra faziam dos chamados comunistas. Tais caracterizações não resistiriam à demonstração. A violência então passa a compor essa definição e carrega com ela, como estratégia, a demonstração das consequências e riscos em decidir-se por ser um inimigo interno.

As guerras fratricidas ocorridas nas América Latina durantes as ditaduras militares revelam que as mesmas estratégias utilizadas pelo atual presidente do Brasil na construção do inimigo interno são de difícil convencimento, pouco claras e dependem de um grau altíssimo de uma parte significativa da sociedade civil desorganizada. A tortura como prática que não cede, hoje, não se aplica à categoria do comunista, mas

2 Entrevista disponível em: https://wwwl.folha.uol.com.br/fsp/brasil/ fc0405200809.htm. Acesso em: 1 mar. 2019. 
ao pobre, ao negro e ao morador das periferias das cidades brasileiras. Essa é a categoria que tornou-se socialmente convincente como alvo privilegiado de violações, mas não reuniu as condições políticas e sociais para converter-se, ao menos até agora, em discurso presidencial e em política social.

Hoje, o próprio presidente e sua família são suspeitos de ligações com o crime organizado e também não há uma pauta social de direita clara e definida para indicar com clareza aqueles (inimigos internos) que a estão obstaculizando ou impedindo sua implantação. O presidente e seu grupo não conseguem caracterizar os amigos e os inimigos apenas na atuação e ataque de pessoas e grupos pelas redes sociais. Aos poucos tudo vai se convertendo numa rinha entre o presidente e os que não são seus amigos ou não concordam com suas ideias.

Paradoxalmente, o instrumento da tortura contra o inimigo interno, hoje, ainda não é viável como prática de 190 governo. Ela ainda é useira e vezeira contra os vulneráveis, como procurei evidenciar, mas sua transposição contra inimigos, de modo sistemático e como política de segurança nacional, ainda precisa convencer a maior parte da população cujas relações sociais e familiares foram formadas no curto período democrático brasileiro e atravessa três gerações.

Famílias inteiras, hoje, são formadas no espectro esquerda e direita, e, a despeito das explicitações de raiva, rancor e agressividade que perduraram no país após o período eleitoral, a marca clara de uma inimizade a ser exterminada, baseada na definição de comunista ou vermelho, ainda não se consolidou entre os mais próximos.

$\mathrm{O}$ atual presidente e sua família também não representam hoje, quase dez meses após o início do novo governo, os ideais identitários ambicionados pela maioria dos brasileiros. A eficácia do uso dos mesmos conceitos e modus operandi do pós-Segunda Guerra, incluindo a noção de inimigo e de soberania nacional, encontra hoje, para ser implementado 
em escala, o obstáculo do abandono desses conceitos pelos próprios países que os geraram e os colocaram em prática. Entre eles, o próprio governo norte-americano, ao qual o presidente brasileiro se conforma como vassalo.

Entre os três vértices que mantêm o atual presidente no poder - o apoio do governo norte-americano; o apoio de parte ainda significativa do eleitorado brasileiro de direita e/ou conservadores; e as forças armadas -, nenhum deles tem em sua história o apoio explícito e sistemático à tortura incorporado às políticas de segurança dos governos, e todos seriam importantes para converter isso em realidade no Brasil, já que o governo teria não apenas de alterar a Constituição de 1988, como teria de romper todos os acordos, declarações e tratados internacionais de direitos humanos em nível internacional e regional até hoje firmados. ${ }^{3}$

Hoje, após dez meses de governo, o presidente eleito e seu ministro da justiça ainda parecem os únicos que sustentariam publicamente o uso da tortura como prática de governo. Mas, para seus antecessores, a responsabilidade por deixar a

3 A nível internacional, o Brasil é membro ou partidário dos principais tratados das Nações Unidas em direitos humanos proibindo a tortura e os maus-tratos. Eles incluem o Pacto Internacional sobre Direitos Civis e Políticos e os dois protocolos opcionais relativos a isso. Também a Convenção contra a Tortura e outras Penas ou Tratamentos Cruéis, Desumanos ou Degradantes e o Protocolo Facultativo relativo a ela; a Convenção Internacional para a Proteção de Todas as Pessoas contra os Desaparecimentos Forçados; a Convenção Sobre os Direitos da Criança; a Convenção Internacional sobre a Eliminação de Todas as Formas de Discriminação Racial; a Convenção sobre a Eliminação de Todas as Formas de Discriminação Contra a Mulher; a Convenção sobre os Direitos das Pessoas com Deficiência; a Convenção Internacional sobre a Proteção dos Direitos de Todos os Trabalhadores Migrantes e Membros de suas Famílias; a Convenção das Nações Unidas relativa ao Estatuto dos Refugiados; e a Convenção sobre o Estatuto dos Apátridas. O Brasil também é signatário do Estatuto de Roma do Tribunal Penal Internacional.

A nível regional, o Brasil é parte dos principais tratados de direitos humanos da Organização dos Estados Americanos, incluindo a Convenção Americana sobre Direitos Humanos; a Convenção Interamericana para Prevenir e Punir a Tortura; a Convenção Interamericana sobre Desaparecimento Forçado de Pessoas; a Convenção Interamericana para Prevenir, Punir e Erradicar a Violência Contra a Mulher; e a Convenção Interamericana Contra o Racismo, a Discriminação Racial e as Formas Conexas de Intolerância. O Estado também reconhece a jurisdição da Corte Interamericana de Direitos Humanos. 
prática da tortura sendo cometida contra os pobres e vulneráveis durante décadas, desde o fim da ditadura, pode revelar para o atual governo uma oportunidade aberta para perseguir juridicamente muitos ativistas que podem ser perseguidos e torturados ao serem conduzidos ao cárcere; locais de exceção onde a arbitrariedade grassa. Pior: hoje corremos o risco iminente de aprofundar a desastrosa e discriminatória política penitenciária, colocando-a no lugar da total ausência de projetos e políticas sociais consistentes. Esse programa pode ser lido nas entrelinhas da campanha presidencial do presidente eleito.

$\mathrm{O}$ discurso de guerra às drogas e guerra aos bandidos já é uma crendice na qual se apoia o governo e muitos brasileiros. Nenhuma novidade quanto a promessas parecidas de candidatos passados com pendores à direita. Doravante, contudo, como estratégia poderá se converter numa crendice apoiada em programas de encarceramento em massa, na violência policial e nos atenuantes oferecidos aos cidadãos comuns e armados acionados pelo Twitter.

\section{Paulo Endo}

é psicanalista e professor livre-docente do Instituto de Psicologia da USP(IP-USP), coordenador do grupo de pesquisa em Direitos Humanos, Democracia, Política e Memória do IEA/USP. Assessor de Territorios Clinicos de la Memória (TeCMe-Argentina), pesquisador da Unit Research on Dreams, Memory and Imagination Studies (Polônia) e membro da Memory Studies Association (Dinamarca/Holanda).

\section{Bibliografia}

ENDO, Paulo Cesar. 2006. Tortura: aspectos psicológicos. Polêm!ca, v. 16.

Não paginado.

ENDO, Paulo Cesar. 2010. Violência, elaboração onírica e o horizonte

testemunhal. Temas em Psicologia, v. 17, n. 2, pp. 343-349.

ENDO, Paulo Cesar. 2014. Banido, bando, bandido, bandeirante. Percurso, v. 3, pp. 61-70. 
ENDO, Paulo Cesar. 2016 Sonhar o desaparecimento forçado de pessoas: impossibilidade de presença e perenidade de ausência como efeito do legado da ditadura civil-militar no Brasil. Psicologia USP, v. 27, pp. 8-15.

ENDO, Paulo Cesar. 2018a. Freud, o inconsciente, a des-memória, a in-memória e os paradoxos do esquecimento, do sonho e do real em Auschwitz. Percurso, v. 60, p. 7.

ENDO, Paulo Cesar. 2018b. O arquivo de sonhos de ex-prisioneiros de Auschwitz do Museu-Memorial de Auschwitz-Birkenau. Percurso, v. 60, pp. 89-96.

FREUD, Sigmund. 2010. Considerações atuais sobre a guerra e a morte. In: FREUD, Sigmund. Introdução ao narcisismo: ensaios de metapsicologia e outros textos (1914-1916). Tradução e notas: Paulo Cezar de Souza. São Paulo: Companhia das Letras.

HUMAN RIGHTS COUNCIL. 2016. Report of the Special Rapporteur on torture and other cruel, inhuman or degrading treatment or punishment on his mission to Brazil. New York: United Nations General Assembly. Disponível em: http://bit.ly/32Sg6kk. Acesso em: 1 mar. 2019.

ROBIN, Marie-Monique. 2008. Escadrons de la mort, l'école française. Paris: La Découverte.

RODLEY, Nigel. 2001. Relatório sobre a Tortura no Brasil. Geneva: Comissão de Direitos Humanos da Organização das Nações Unidas. Disponível em: http://bit.ly/32ElMhS. Acesso em: 1 mar. 2019. 


\section{OS CAMINHOS POSSÍVEIS DE UM DESGOVERNO DIANTE DA} PRÁTICA DA TORTURA: APONTAMENTOS E PERSPECTIVAS NUM CONTEXTO DE APOIO GOVERNAMENTAL A GRAVES VIOLAÇÕES DE DIREITOS HUMANOS NO BRASIL

PAULO ENDO

Resumo: $\mathrm{O}$ artigo examina as possibilidades de adoção da tortura sistemática no Brasil após o resultado das eleições de 2019. O fato inédito na história do país, em que foi conduzido à Presidência da República um candidato sabidamente favorável à tortura, propõe desafios inéditos à pesquisa e à ação políticas no Brasil a partir de 2019. Ainda, esmiuçarei brevemente o contexto de naturalização da tortura no período democrático no país e algumas hipóteses sobre os desdobramentos dessa prática nos próximos anos.

Palavras-chave: Tortura; Democracia; Direitos Humanos; Psicanálise.

\section{THE POSSIBLE PATHS OF A RANDOM GOVERNMENT} IN FRONT OF THE PRACTICE OF TORTURE: NOTES

\section{AND PERSPECTIVES IN A CONTEXT OF GOVERNMENT SUPPORT FOR SERIOUS VIOLATIONS OF HUMAN RIGHTS IN BRAZIL}

Abstract: The article examines the possibilities of adopting systematic torture in Brazil after the outcome of 2019 elections. The unprecedented fact in the history of the country in which a candidate who openly supports torture was elected proposes unprecedented challenges to research and political acts in Brazil from 2019. I will also briefly examine the context of naturalization of torture in the democratic period in the country and some hypotheses on the consequences of this practice in the coming years.

Keywords: Torture; Democracy; Human Rights; Psychoanalysis.

Recebido: 26/03/2019 Aprovado: 14/10/2019 